\title{
Efficacy of Lycium barbarum polysaccharide and synergism with paclitaxel/cisplatin in ovarian cancer in mice
}

\author{
Lei Zhu', Yunguo Han ${ }^{2}$ and Hongmei Wang ${ }^{3 *}$ \\ ${ }^{1}$ Department of Pharmacy, Yancheng First People's Hospital, Yancheng, Jiangsu Province, 224006, ${ }^{2}$ Department of Pharmacy, \\ Binzhou Central Hospital, Binzhou, Shandong Province, 251700, ${ }^{3}$ Department of Endocrinology, People's Hospital Affiliated to \\ Inner Mongolia Medical University, Hohhot, Inner Mongolia Autonomous Region, 010000, China
}

*For correspondence: Email: HMWang00@126.com

\begin{abstract}
Purpose: To determine the efficacy of Lycium barbarum polysaccharide (LBP) in ovarian cancer, and the synergistic effect when used in combination with paclitaxel/cisplatin (PXTDDP).

Methods: ID-8 cells were injected subcutaneously into 5 groups of female C57BL/6 mice (5 mice/group): control (Con), chemotherapy (CH, PTX/DDP), combination therapy 1 (co-CH1, PTX/DDP + $50 \mathrm{mg} / \mathrm{kg}$ LBP), combination therapy 2 (co-CH2, $100 \mathrm{mg} / \mathrm{kg} \mathrm{LBP}$ ) and combination therapy 3 (co-CH3, $150 \mathrm{mg} / \mathrm{kg}$ LBP). Tissue morphological changes were monitored by hematoxylin and eosin (H\&E) staining. Protein and mRNA levels of Keap1, Nrf2) and heme oxygenase-1 (HemO-1) were analyzed by western blotting and real-time polymerase chain reaction (PCR), as applicable.

Results: Growth rate and volume of tumors were significantly reduced in the chemotherapy and combination therapy groups, while organ index increased significantly in co-CH group. Morphological structure of tumor, liver and kidney became normal after combination therapy. Levels of alanine transaminase (ALT), aspartate transaminase (AST), alkaline phosphatase (ALP), uric acid (UA), creatinine $(\mathrm{Cr})$ and blood urea nitrogen (BUN) were significantly decreased in $\mathrm{Co}-\mathrm{CH}$ group relative to $\mathrm{CH}$ group. Lymphocytes, monocytes (MNC), neutrophils, basophils and eosnophils were significantly regulated by combination therapy. In $\mathrm{CH}$ and co-CH1-3 groups, the mRNA and protein levels of Keap1, $\mathrm{HO}-1$ and Nrf2 were significantly increased relative to those of control mice.

Conclusion: LBP in combination with PXTDDP enhances the efficacy of the latter, and reduced its toxicity when used for the treatment of ovarian malignant tumor in mice, by activating Keap1/Nrf2 pathway and promoting immunity.
\end{abstract}

Keywords: Lycium barbarum polysaccharide (LBP), Paclitaxel/Cisplatin, Keap1/Nrf2 pathway, Cytotoxicity

Tropical Journal of Pharmaceutical Research is indexed by Science Citation Index (SciSearch), Scopus, International Pharmaceutical Abstract, Chemical Abstracts, Embase, Index Copernicus, EBSCO, African Index Medicus, JournalSeek, Journal Citation Reports/Science Edition, Directory of Open Access Journals (DOAJ), African Journal Online, Bioline International, Open-J-Gate and Pharmacy Abstracts

\section{INTRODUCTION}

It is generally known that ovarian cancer is a serious health and life threat to women. In the United States of America, more than $63 \%$ of women with cancer of the ovaries died in 2015 [1]. Approximately $1.5 \%$ of women may come down with epithelial ovarian cancer (EOC) at one point or the other, a serious statistic due to the fact that this form of ovarian cancer ranks amongst the leading causes of cancer-induced fatalities in women [2]. Surgery and chemotherapy have been applied successfully in treating advanced cancers, although they have not resulted in significant increases in five-year 
survival rate [3-5]. It is difficult for some patients to accept chemotherapy due to its severe adverse effects [4]. Therefore, in order to improve the quality of life of the cancer patient, it is crucial to evolve alternative and safer treatment regimens [5].

The combination of PXT and DDP has been in use as the first-line drugs for ovarian cancer. However, the combination kills both malignant cells and normal cells, leading to poor prognosis and poor quality of life for the patient [6, 7].Obtained from the bark of yew roots, paclitaxel is a unique medicinal extract authorized for use in the control of the growth of cancer cells [7]. The side effects of the drug include bone marrow suppression, peripheral neuropathy and arthralgia [8]. DDP inhibits DNA synthesis and is a cell cycle non-specific agent for tumors. The main side effects associated with DDP are liver and kidney toxicity, and bone marrow suppression [9]. Therefore, DDP is not suitable for the treatment and good prognosis of patients. Consequently, it is important to explore a different strategy for treatment of ovarian cancer. The screening of medicinal plants for useful anticancer agents with lesser side effects has been a research hotspot in various cancer research laboratories.

LBP, the major active ingredient extracted from $L$. barbarum, has been found to possess antitumor, immuno-regulative, hepato-protective, anti-oxidative and neuro-protective properties [10]. In in vitro and in vivo experiments, LBP showed synergistic immunotherapeutic effects with interferon- $\alpha 2 b$ on renal cell carcinoma [11]. In addition, it has been shown that LBP has significant antioxidant properties [12].

Oxidative stress was intimately linked with cancers [15]. PTX and DDP induce oxidative stress $[11,12]$. Long-term chemotherapy causes oxidative damage, which reduces the levels and capacities of antioxidant enzymes. The resultant oxidative stress may decrease immunity and enhance adverse chemotherapy reactions [1315]. The Kelch-like ECH-associated protein 1 (Keap1)/nuclear factor-erythroid-2-related factor 2 (Nrf2) system, which is the master regulator of the anti-stress response, induces the activities of various enzymes via Nrf2-mediated transcriptional regulation under stress conditions [16]. Activation of Keap1/Nrf2 induces the synthesis of detoxification and antioxidant enzymes to protect cells and tissues. Reactive cysteinyl groups in Keap1 are stimulated by diverse signals, leading to uncoupling of Nrf2 from the Keap1/Nrf2 conjugate [17]. Free Nrf2 activates the transcription of its target genes [18].
In this study, the efficacy of LBP in ovarian cancer, and its synergistic effects when used in combination with paclitaxel/cisplatin (PXT/DDP) were investigated.

\section{EXPERIMENTAL}

\section{Animal and tumor model}

Female C57BL/6 mice (6 - 8 weeks old; $20-22$ g) were obtained from the Laboratory Animal Center of 301 Hospital (Beijing, China). The protocol for all animal studies conformed with the provisions of National Research Council for Animal Care [19]. Approval for the study was obtained from the Yancheng First People's Hospital (Ethical no. 14030251). ID-8 cells were generated from MOSEC ovarian cancer cell lines of C57BL/6 mice (Zhejiang Tianhang Biological Technology Co., Ltd, Zhejiang, China). The cells were maintained at $37^{\circ} \mathrm{C}$ in RPMI 1640 medium with $5 \%$ fetal bovine serum, insulin-transferrinselenium and $0.5 \%$ streptomycin, product of Gibco (USA), in a $5 \%-\mathrm{CO}_{2}$ atmosphere. Hair was removed from dorsal surfaces of the mice using a shaver. Thereafter, $3 \times 10^{6}$ ID- 8 cells were injected S.c. into the left shoulder of each mice by a subcutaneously. The criteria for mice selection were appearance of round tumors and tumor diameter of $5-7 \mathrm{~mm}$.

\section{Animal grouping and treatment}

Five groups of 25 mice (5 per group) injected with ID-8 cells were used for the study. These were: untreated control group (Con), which were injected in the cauda vein with $0.1 \mathrm{~mL} 0.9 \%$ normal saline (NS) once a week for four weeks; chemotherapy group $(\mathrm{CH})$, which were injected in the cauda vein with $0.1 \mathrm{~mL}$ PTX $(5 \mathrm{mg} / \mathrm{kg})+$ DDP (3 mg/kg), once weekly for four weeks; and 3 combination therapy groups, combination therapy 1 (co-CH1; combination therapy 2 (co$\mathrm{CH} 2$ ) and combination therapy 3 (co- $\mathrm{CH} 3)$, each of which received via the cauda vein, $0.1 \mathrm{~mL}$ PTX (5 mg/kg) + DDP (3 mg/kg) once a week for four weeks. In addition, the three combination therapy groups were intragastrically administered different doses of $\operatorname{LBP}(50,100$ and $150 \mathrm{mg} / \mathrm{kg}$, respectively) [16].

\section{Animal sacrifice and isolation of organs}

Two weeks prior to the end of the treatment, whole blood was collected from the retro-orbital plexus into $3 \mathrm{~mL}$ centrifuge tubes containing heparin, and preserved in the refrigerator at $4{ }^{\circ} \mathrm{C}$. The mice were weighed every two days until the end of the experiment. They were sacrificed by cervical dislocation and quickly submerged in 
ethanol (75\%) for $5 \mathrm{~min}$. The spleen was excised in a sterile hood, after which the tumors, livers, kidneys, ovaries, spleens and thymuses were removed, weighed and used for subsequent studies.

\section{H\&E staining}

Fixing of the tumors was done in formaldehyde (10\%) for a maximum of 12 h., while formalin $(10 \%)$ was used for fixing the liver and kidney samples for $72 \mathrm{~h}$. The tumor and organ samples were embedded in paraffin, sectioned, stained with $\mathrm{H} \& \mathrm{E}$ and read by two experienced pathologists.

\section{Liver and kidney function test}

Blood levels of $\mathrm{Cr}$, AST, ALP, ALT, BUN and uric acid (UA) were analyzed in all groups using an Olympus 400 Clinical Chemistry analyzer.

\section{Biochemical assays}

Venous blood was subjected to complete blood count (CBC), which was performed with an automated analyzer MS4 (Melet Schloesing 4, Germany) used for in vitro diagnostic tests. The instrument was used to count the number and types blood cells. Sufficient quality control measures were taken on each test procedure to ensure the reliability of the results.

\section{RNA isolation}

The total tissular RNA were lysed with Trizol reagent (Invitrogen). The RNA was determined spectrophotometrically using by NanoDrop 2000 Spectrophotometer (Thermo Scientific, MA, USA). Reverse-transcription was performed with TakaRa RT kits (Dalian, China).

\section{Real-time PCR (RT-PCR)}

A Light Cycler (Roche) and SYBR RT-PCR kit (Takara) were used for quantitative real-time RTPCR analysis. Data were normalized to GAPDH expression.

\section{Western blot}

Liver and kidney tissue homogenates were lysed in RIPA buffer containing protease inhibitors. Protein concentration was determined in the supernatant by BCA assay (Pierce). The protein (30-50ug) was separated by $10 \%$ SDS polyacrylamide gel electrophoresis PAGE gel, and transferred to nitrocellulose membrane (Millipore, Shanghai, China) for the detection of keap1, Nrf2 and HO-1. The blots were visualized by enhanced chemiluminescence (ECL, Thermo Scientific, Shanghai, China).

\section{Statistical analysis}

Data are expressed as mean \pm SEM, and analyzed for statistically significant differences between control and treatment groups using oneway analysis of variance (ANOVA) and IBM SPSS 19 software (SPSS Inc., Chicago, IL). $P<$ 0.05 was taken as indicative of significant difference.

\section{RESULTS}

\section{Anti-tumor effects of combination of LBP with PTX/DDP}

Tumors from the different groups were arranged on a white sheet of paper (Plate 1). The results showed that tumor weight and tumor volume in the $\mathrm{CH}, \mathrm{co}-\mathrm{CH} 1, \mathrm{co}-\mathrm{CH} 2$ and $\mathrm{co}-\mathrm{CH} 3$ groups were reduced. Tumor weight and tumor volume in the $\mathrm{co}-\mathrm{CH} 1, \mathrm{co}-\mathrm{CH} 2$ and $\mathrm{co}-\mathrm{CH} 3$ groups were significantly lower than those in $\mathrm{CH}$ group ( $p<$ 0.05) (Figure 1a and 1b). In the $\mathrm{CH}, \mathrm{Co}-\mathrm{CH} 1$, co$\mathrm{CH} 2$ and $\mathrm{co}-\mathrm{CH} 3$ groups, tumor growth rate was significantly reduced when compared to the control group ( $p<0.05$ ), and was lower in the co$\mathrm{CH}$ than in the $\mathrm{CH}$. The reduction due to LBP was in a dose-dependent manner (Figure 1c). The increasing order of \% tumor inhibition was control group $(0)<\mathrm{CH}$ group $(13.17 \pm 4.49 \%)<$ co-CH1 group $(32.86 \pm 10.10 \%)<$ co-CH2 group $(47.44 \pm 6.03 \%)<$ co-CH3 group $(61.36 \pm$ $3.98 \%$ ) (Figure 1d).

\section{Effect of combined therapy on tumor and organ morphologies STOPPED}

Morphological changes of tissues are shown in Plate 2. In the $\mathrm{CH}$ group, the tumor morphology was better than that of untreated control group. However, there were more deleterious changes in the liver and kidney of the $\mathrm{CH}$ group when compared with the control group. In the $\mathrm{Co}-\mathrm{CH} 1$, co- $\mathrm{CH} 2$ and $\mathrm{co}-\mathrm{CH} 3$ groups, the liver and kidney tissues tended towards normal architecture, with clearer intercellular spaces and karyopyknosis fragmentation. The morphology of the tissues became more normal in the $\mathrm{co}-\mathrm{CH}$ group when compared with the $\mathrm{CH}$ group.

\section{Effect of combination of LBP and PTX/DDP on organ indices}

Liver index, kidney index and ovary index were significantly elevated in group $\mathrm{CH}$ when compared to untreated control group ( $p<0.05$, Figures $2 \mathrm{a}, \mathrm{b}$ and $\mathrm{c}$ ). There was no significant 
difference in spleen index and thymus index between the control group and the $\mathrm{CH}$ group (Figures $2 \mathrm{~d}$ and e). In the $\mathrm{co}-\mathrm{CH} 1, \mathrm{co}-\mathrm{CH} 2$ and co-CH3 groups, liver, kidney, ovary, spleen and thymus indices were significantly increased in a dose-dependent manner by combination therapy $(p<0.05)$.

ALT, AST, ALP, BUN, Scr and UA are common clinical criteria for evaluating liver and kidney functions. Results shown in Figure 3 reveal that ALT, AST, ALP, BUN, Cr and UA values in the $\mathrm{CH}$ group were significantly higher than the corresponding values in the control group $(p<$ 0.05). The levels of ALT, AST, ALP, BUN, Scr and UA were sequentially and significantly reduced in the $\mathrm{co}-\mathrm{CH} 1, \mathrm{co}-\mathrm{CH} 2$, $\mathrm{co}-\mathrm{CH} 3$ group, in a dose-dependent manner $(p<0.05)$.

\section{Effect of combination of LBP and PTX/DDP on immune response}

The WBC, RBC and platelet counts in the $\mathrm{CH}$ group were significantly lower than those of the control group (Figures $4 \mathrm{a}-\mathrm{c}$ ). The ratios of lymphocytes to basophils were significantly decreased, while the ratios of monocytes to neutrophils were significantly increased $(p<$ 0.05; Figures $5 \mathrm{~d}-\mathrm{g}$ ).
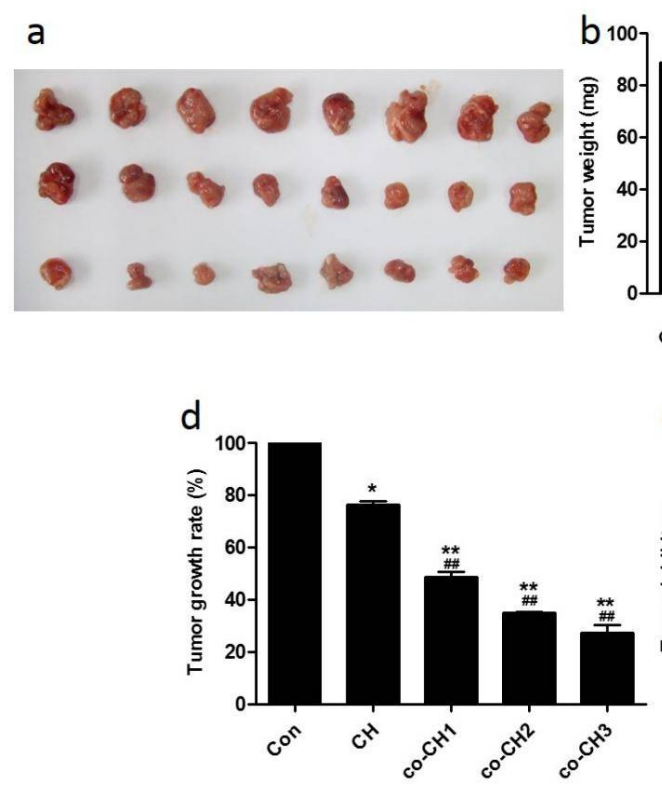

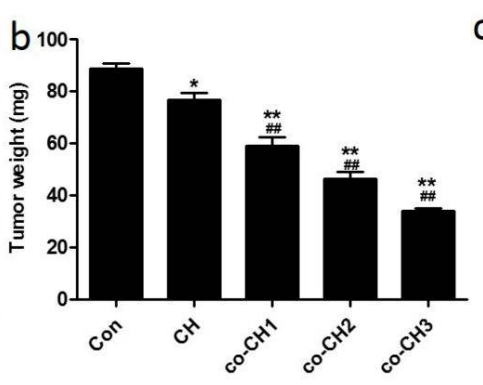

e

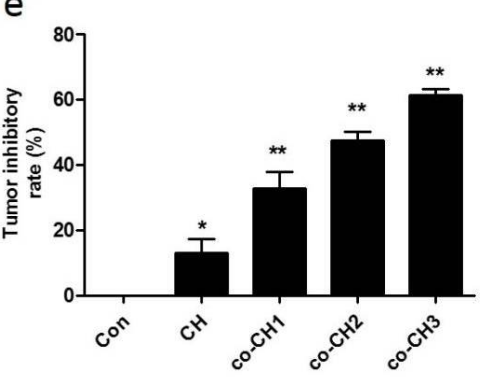

Figure 1: Anti-tumor effects of LBP-PTX/DDP combination. Data are mean \pm SEM $(n=6){ }^{*} \# p<0.05$; ${ }^{* *} \# \# p<0.01$

Con
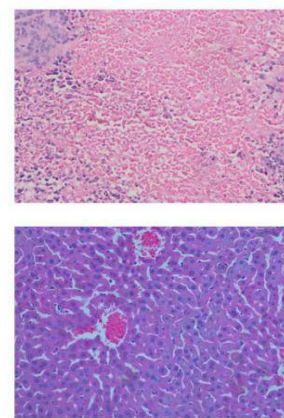

liver

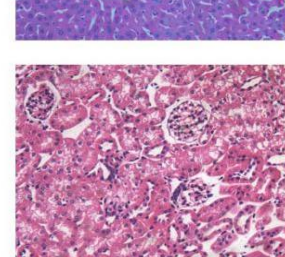

$\mathrm{CH}$
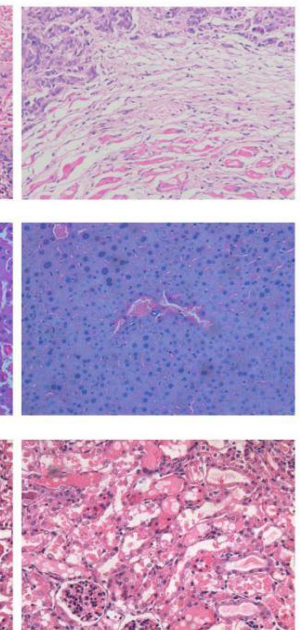

$\mathrm{Co}-\mathrm{CH} 1$
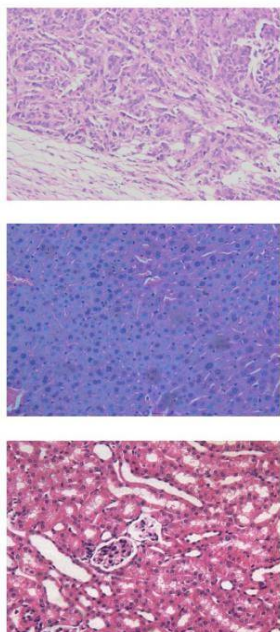

$\mathrm{CO}-\mathrm{CH} 2$

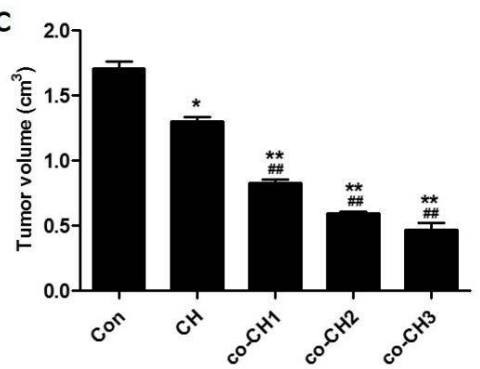

$\mathrm{CO}-\mathrm{CH} 3$
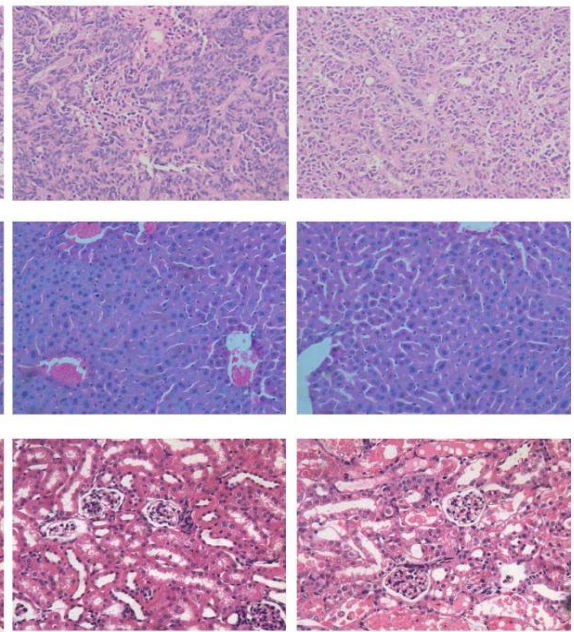

Plate 2: Effect of combination of LBP and PTX/DDP on morphological changes in tumors and tissues (Data are mean $\pm S E M, n=3$ ) 

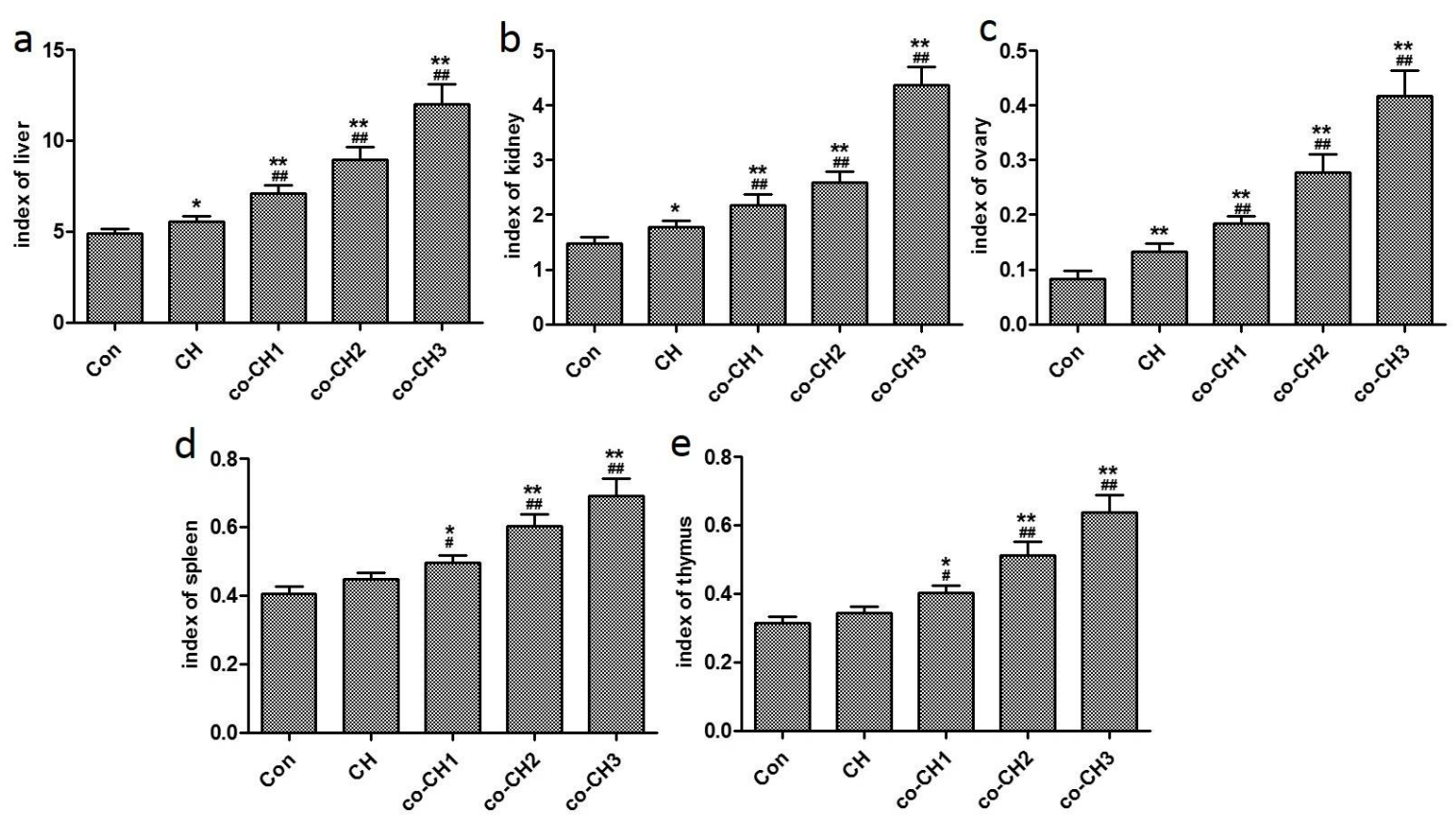

Figure 2: Effect of combination of LBP and PTX/DDP on some organ indices in mice (data are mean $\pm \mathrm{SEM}, \mathrm{n}=6 ;{ }^{*} \# p<0.05,{ }^{*} \# \# p<0.01$ )
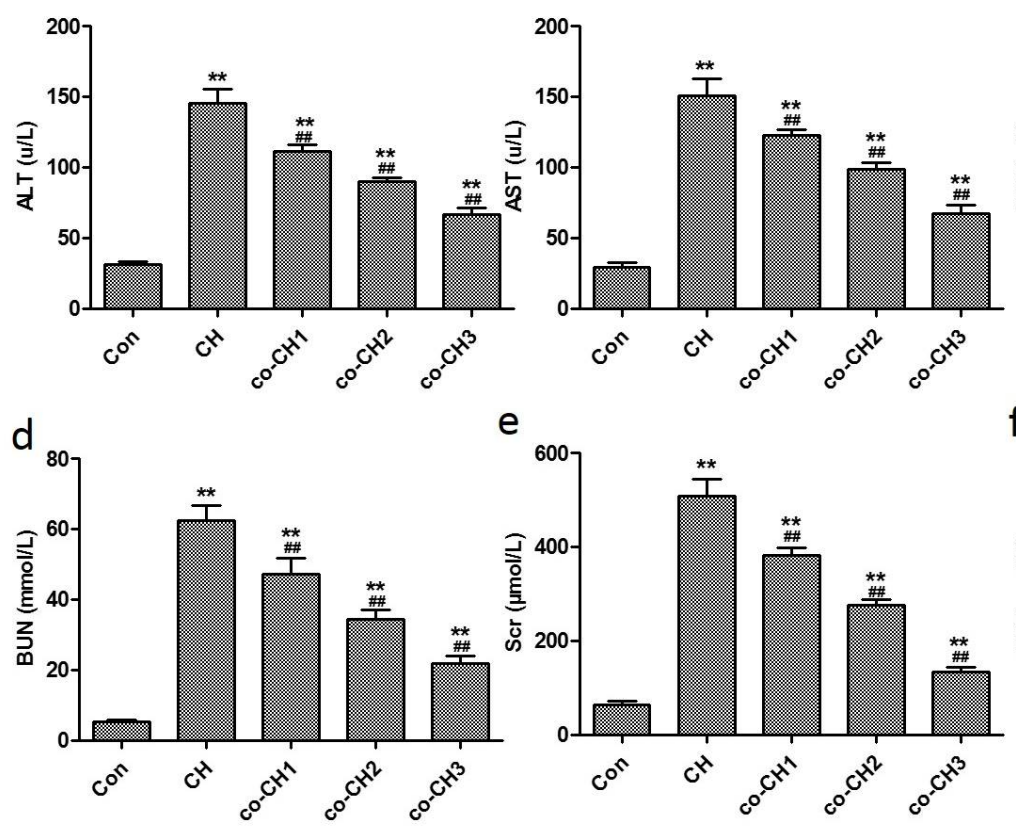

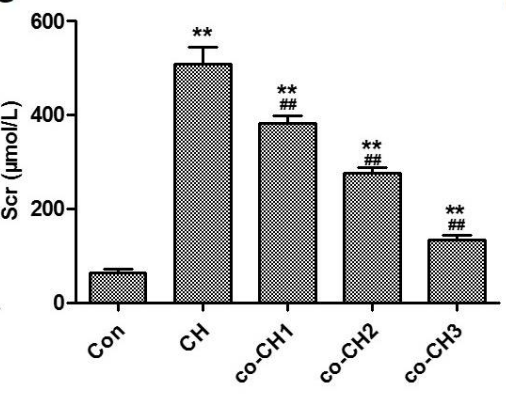

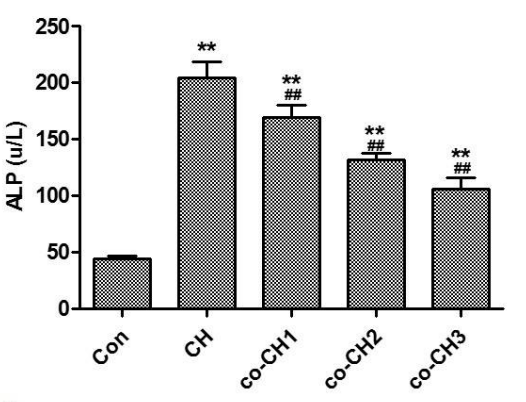

$f$

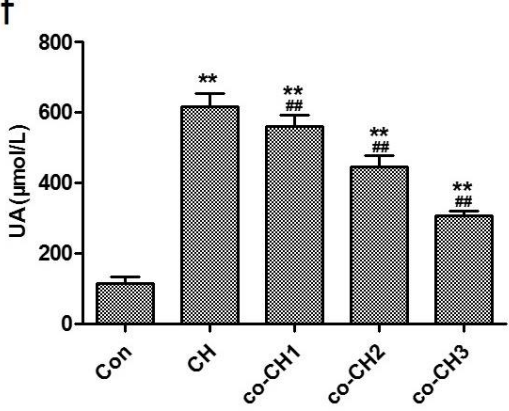

Figure 3: LBP combined with PTX/DDP inhibit the clinical index. Data are mean \pm SEM $(n=6)$. ${ }^{*} \# p<$ $0.05 ;{ }^{* *} \# \# p<0.01$

\section{Effect of combination of LBP and PTX/DDP on Keap1, Nrf2 and HO-1 levels}

In liver and kidney tissues, mRNAs for Nrf2, Keap1 and HO-1 were gradually increased in the control, $\mathrm{CH}$, co-CH1, co- $\mathrm{CH} 2$ and $\mathrm{co}-\mathrm{CH} 3$ groups (Figure 5). In the $\mathrm{co}-\mathrm{CH}$ group, higher mRNAs of Keap1, Nrf2 and $\mathrm{HO}-1$ were obtained when compared with values for control and $\mathrm{CH}$ groups in liver and kidney tissues $(p<0.05$, Figure 5$)$.
In liver tissues, Keap1, Nrf2 and HO-1 proteins were up-regulated by LBP (Figures $6 a$ and $b$ ). A similar pattern was evident in kidney tissue (Figure $6 \mathrm{c}$ and $\mathrm{d}$ ). In liver and kidney tissues, Nrf2, Keap1 and HO-1 protein expressions in the $\mathrm{co}-\mathrm{CH}$ group was significantly and dosedependently higher than the corresponding expressions in the $\mathrm{CH}$ group $(p<0.05$, Figures $6 b$ and d). 


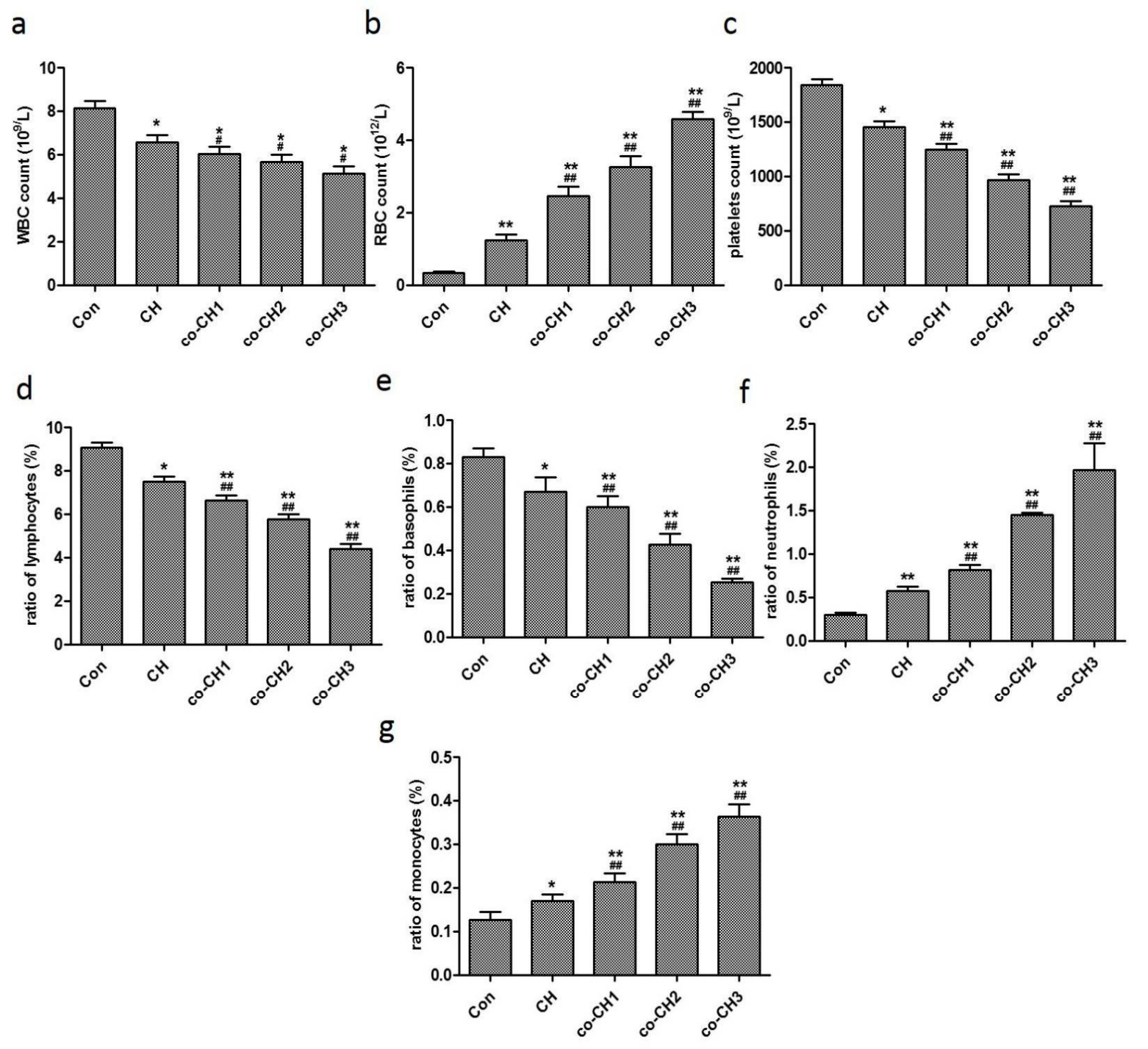

Figure 4: Effect of combination of LBP and PTX/DDP on immune response in mice (data are mean \pm SEM, $n=6$ ) of one typical result from three independent experiments with similar results. ${ }^{*}, \# p<0.05$; ${ }^{\star \star}, \# \# p<0.01$

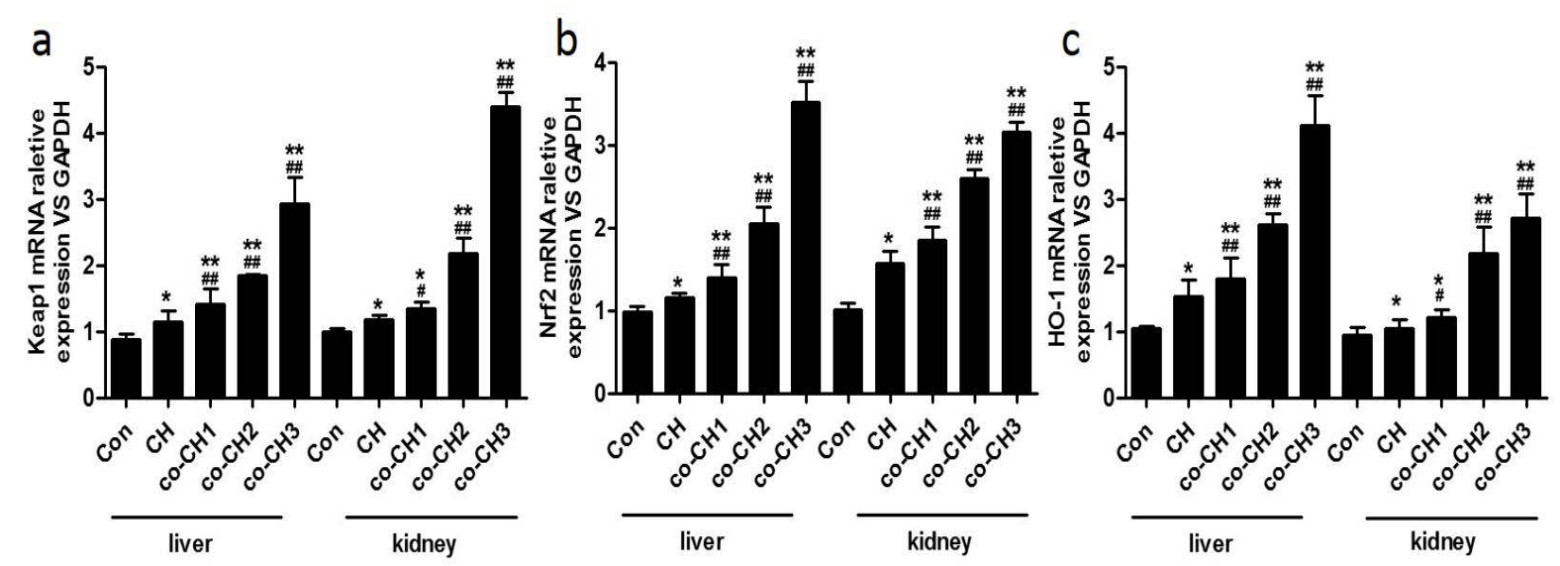

Figure 6: Effect of combination of LBP and PTX/DDP on mRNA levels of Keap1, Nrf2 and HO-1. Data are mean $\pm \operatorname{SEM}(n=3)$ 

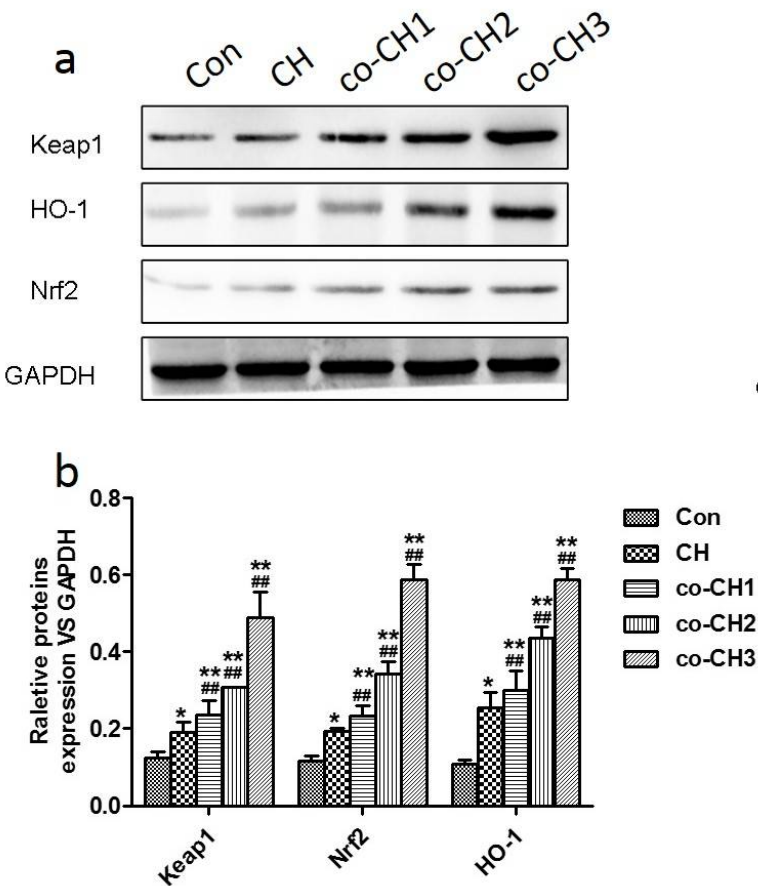
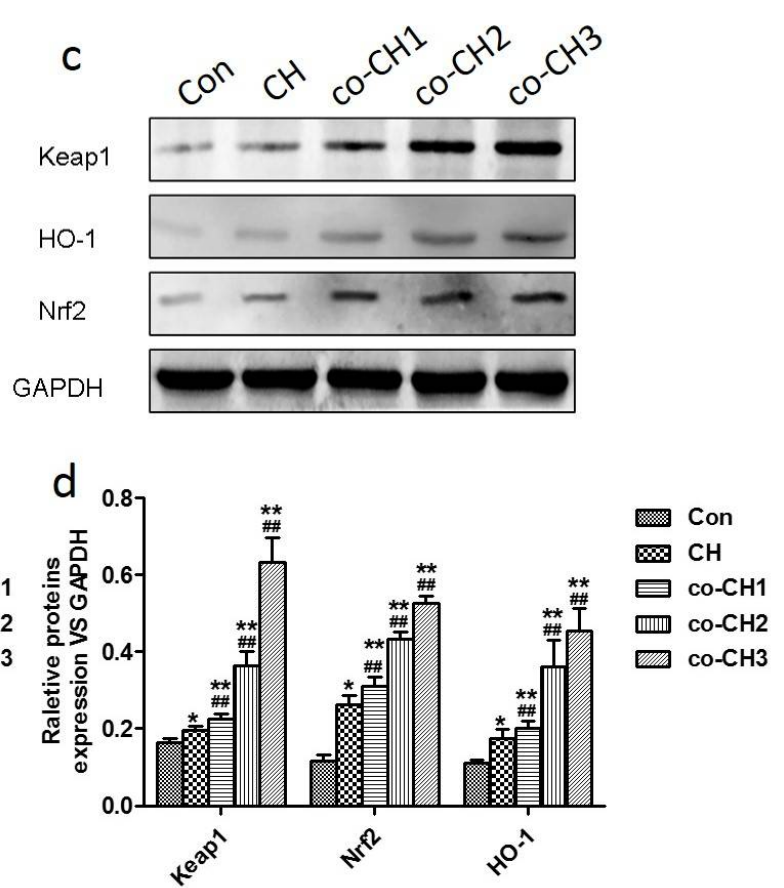

Figure 6: Effect of combination of LBP and PTX/DDP on the expressions of Nrf2, Keap1, and HO-1. Data are mean \pm SEM $(n=3)$

\section{DISCUSSION}

Chemotherapy is very crucial in the treatment of ovarian cancer in that its effect directly decides the prognosis of the disease, but the adverse effect of drug and multi-drug resistance affect the therapeutic efficacy of ovarian carcinoma $[4,5]$. The choice of ovarian cancer for this investigation was based on the fact that ovarian cancer frequently responds poorly to DDP and Taxol, resulting in unsatisfactory treatment outcomes [3-6]. Therefore, the present study was carried out to investigate if the effect of chemotherapy could be enhanced by combination with LBP in the treatment of ovarian cancer. The results obtained revealed that combined treatment with LBP PTX/DDP significantly increased the observed anti-tumor effects and immune response, altered the morphology of tissues and lowered organ indices by activation of Keap, Nrf2 and HO-1. The tumor weight and volume in $\mathrm{CH}$ group were lower than in the untreated control group, and tumor growth was significantly inhibited by PTX/DDP in this group. Interestingly, the anti-tumor effect seen in the co-CH group was better than that seen in the $\mathrm{CH}$. This clearly shows that combination of chemotherapy and LBP, given at the same time, can significantly reduce the growth of ovarian cancer. Moreover, the enhancement of effect of chemotherapy by LBP was dose-dependent.

Serum levels of transaminases and ALP are recognized markers of liver damage [20], while kidney damage is assessed by serum levels of $\mathrm{Cr}$, BUN, and UA [21]. In this study, although the shape of tumor tissues in $\mathrm{CH}$ group was better than the shape seen in the control group, more tissue lesions were evident in the kidney tissues of the $\mathrm{CH}$ group. In addition, serum transaminases, ALP, Cr, BUN, and UA were significantly increased in the $\mathrm{CH}$ group. These results indicate that although chemotherapy had a beneficial treatment effect, it brought about liver and kidney impairment. In the $\mathrm{co}-\mathrm{CH}$ group, the shape of tumor, liver and kidney tissues improved dose-dependently, and markers of liver and kidney damage were down-regulated significantly by the combination therapy. Thus LBP offered protection to liver and kidney tissues, and enhanced the anti-tumor effect of PTX/DDP. The liver and kidney injury caused by PTX/DDP was catabatic in the co-CH group. It was also shown that the combination of LBP and PTX/DDP altered (in a positive manner) the morphology of tissues and decreased organ indices.

The spleen and thymus are immune-related organs, which influence platelet count, red blood cell count and even white blood cell count. Indices of liver, kidney, ovary, spleen and thymus were decreased in the $\mathrm{CH}$ group, the counts of WBC, $\mathrm{RBC}$ and platelet in the $\mathrm{CH}$ group were lower than those of control group, and the lymphocyte ratio was decreased. In the $\mathrm{co}-\mathrm{CH}$ group, organ indices were increased significantly by LBP; WBC, RBC, and platelet counts were 
increased, and lymphocyte ratios were increased in a dose-dependent manner. These results suggest that LBP exerted a positive effect by reversing the damage to the injured organs.

Nrf2 and Keap1 are central regulatory factors in anti-oxidative reactions. The detoxifying enzymes, glutathione synthetase and peroxiredoxins activated and released by the Keap1/Nrf2 pathway, protect cells against oxidative stress and maintain homeostasis [1315]. This study demonstrated that LBP upregulated the mRNA and protein levels of Keap1, $\mathrm{Nrf} 2$ and $\mathrm{HO}-1$ in liver and kidney in the $\mathrm{co}-\mathrm{CH}$ group. Heme oxygenase-1 (HO-1), as a phase 1 detoxifying enzyme, is a downstream gene of Nrf2, which is essential for detoxification in the liver. LBP may have activated the function of Nrf2 so as to counteract the effects of the tumor. The mRNA and protein levels of Keap1, Nrf2 and $\mathrm{HO}-1$ in liver and kidney were increased in a dose-dependent manner in the $\mathrm{co}-\mathrm{CH}$ group. In all, these results indicate that LBP exerted antioxidant effects via activation of Keap1/Nrf2, thereby enhancing the capacity of immune response.

The observed effect of LBP is considered important for improvement of effectiveness of chemotherapy. The combination of LBP with PTX/DDP significantly enhanced the anti-tumor effect and immune response, altered the morphology of tissues and decreased organ indices through the activation of Keap1, Nrf2 and $\mathrm{HO}-1$.

\section{CONCLUSION}

Combined treatment with LBP and PTX/DDP significantly enhances chemotherapy efficacy and reduces chemotherapy-induced toxicity by strengthening immune response, increased detoxification capability and activated Keap1/Nrf2 pathway. These findings indicate that LBP may regulate immunity, and is thus a potential source of new drugs for the treatment of ovarian cancer.

\section{DECLARATIONS}

\section{Acknowledgement}

The authors thank MedScience Editors for English language editing of the manuscript.

\section{Conflict of Interest}

No conflict of interest associated with this work.

\section{Contribution of Authors}

The authors declare that this work was done by the authors named in this article and all liabilities pertaining to claims relating to the content of this article will be borne by them.

\section{Open Access}

This is an Open Access article that uses a funding model which does not charge readers or their institutions for access and distributed under the terms of the Creative Commons Attribution License (http://creativecommons.org/licenses/by/ 4.0) and the Budapest Open Access Initiative (http://www.budapestopenaccessinitiative.org/rea d), which permit unrestricted use, distribution, and reproduction in any medium, provided the original work is properly credited.

\section{REFERENCES}

1. Siegel RL, Miller KD, Jemal A: Cancer statistics, 2015. CA Cancer J Clin 2015; 65: 5-29.

2. George SH, Shaw P: BRCA and Early Events in the Development of Serous Ovarian Cancer. Front Oncol 2014; 4: 5.

3. Vaughan S, Coward Jl, Bast RC, Jr., Berchuck A, Berek JS, Brenton JD, Coukos G, Crum CC, Drapkin R, Etemadmoghadam $D$, et al: Rethinking ovarian cancer: recommendations for improving outcomes. Nat Rev Cancer 2011; 11: 719-725.

4. Schwab CL, English DP, Roque DM, Pasternak M, Santin $A D$ : Past, present and future targets for immunotherapy in ovarian cancer. Immunotherapy 2014; 6: 1279-1293.

5. Banerjee S, Kaye SB: New strategies in the treatment of ovarian cancer: current clinical perspectives and future potential. Clin Cancer Res 2013; 19: 961-968.

6. Durdux C: [Cisplatin and derivatives with radiation therapy: for what clinical use?]. Cancer Radiother 2004; 8 Suppl 1: S88-94.

7. Parness J, Horwitz SB: Taxol binds to polymerized tubulin in vitro. J Cell Biol 1981; 91: 479-487.

8. Reichman BS, Seidman AD, Crown JP, Heelan $R$, Hakes $T B$, Lebwohl DE, Gilewski TA, Surbone A, Currie V, Hudis $C A$, et al.: Paclitaxel and recombinant human granulocyte colony-stimulating factor as initial chemotherapy for metastatic breast cancer. J Clin Oncol 1993; 11: 1943-1951.

9. Litterst $C L$ : Alterations in the toxicity of cisdichlorodiammineplatinum-II and in tissue localization of platinum as a function of $\mathrm{NaCl}$ concentration in the vehicle of administration. Toxicol Appl Pharmacol 1981; 61: 99-108.

10. Lin CL, Wang CC, Chang SC, Inbaraj BS, Chen BH: Antioxidative activity of polysaccharide fractions isolated from Lycium barbarum Linnaeus. Int $\mathrm{J}$ Biol Macromol 2009; 45: 146-151.

Trop J Pharm Res, July 2017; 16(7): 1652 
11. Harisa Gl: Blood viscosity as a sensitive indicator for paclitaxel induced oxidative stress in human whole blood. Saudi Pharm J 2015; 23: 48-54.

12. Pratibha $R$, Sameer $R$, Rataboli PV, Bhiwgade $D A$, Dhume CY: Enzymatic studies of cisplatin induced oxidative stress in hepatic tissue of rats. Eur $J$ Pharmacol 2006; 532: 290-293.

13. lizumi $T$, Takahashi S, Mashima K, Minami K, Izawa $Y$, Abe T, Hishiki T, Suematsu M, Kajimura M, Suzuki N: A possible role of microglia-derived nitric oxide by lipopolysaccharide in activation of astroglial pentosephosphate pathway via the Keap1/Nrf2 system. J Neuroinflammation 2016; 13: 99.

14. Wakabayashi N, Dinkova-Kostova AT, Holtzclaw WD, Kang MI, Kobayashi A, Yamamoto M, Kensler TW, Talalay P: Protection against electrophile and oxidant stress by induction of the phase 2 response: fate of cysteines of the Keap1 sensor modified by inducers. Proc Natl Acad Sci U S A 2004; 101: 2040-2045.

15. Chartoumpekis DV, Kensler TW: New player on an old field; the keap1/Nrf2 pathway as a target for treatment of type 2 diabetes and metabolic syndrome. Curr Diabetes Rev 2013; 9: 137-145.
16. Koc A, Duru M, Ciralik H, Akcan R, Sogut S: Protective agent, erdosteine, against cisplatin-induced hepatic oxidant injury in rats. Mol Cell Biochem 2005; 278: 7984.

17. Cheng D, Kong $\mathrm{H}$ : The effect of Lycium barbarum polysaccharide on alcohol-induced oxidative stress in rats. Molecules 2011; 16: 2542-2550.

18. Behera S, Bulliyya G: Magnitude of Anemia and Hematological Predictors among Children under 12 Years in Odisha, India. Anemia 2016; 2016: 1729147.

19. In Guide for the Care and Use of Laboratory Animals. 8th edition. Washington (DC); 2011: The National Academies Collection: Reports funded by National Institutes of Health].

20. Shlaes DM, Binczewski B, Rice LB: Emerging antimicrobial resistance and the immunocompromised host. Clin Infect Dis 1993; 17 Suppl 2: S527-536.

21. Hou H, Mao L, Wang J, Liu W, Lu Y, Yu J, Zhou Y, Mao $L$, Wang F, Sun Z: Establishing the reference intervals of NK cell functions in healthy adults. Hum Immunol 2016; 77: 637-642. 